NBER WORKING PAPER SERIES

\title{
WAGES, SKILLS, AND TECHNOLOGY IN THE UNITED STATES AND CANADA
}

\author{
Kevin M. Murphy \\ W. Craig Riddell \\ Paul M. Romer
}

Working Paper 6638

http://www.nber.org/papers/w6638

\section{NATIONAL BUREAU OF ECONOMIC RESEARCH 1050 Massachusetts Avenue \\ Cambridge, MA 02138 \\ July 1998}

We thank Michael Pries, Alan Stark, and Laura Veldkamp for expert research assistance, Larry Katz for helpful conversations, and George Akerlof, Paul Beaudry, Pierre Fortin, Elhanan Helpman, Chad Jones, Richard Lipsey, and Alwyn Young for comments on earlier drafts. The Canadian Institute for Advanced Learning supported this work. Riddell also acknowledges financial support from the SSHRCC through the Western Research Network on Education and Training. Any opinions expressed are those of the author and not those of the National Bureau of Economic Research.

(C) 1998 by Kevin M. Murphy, W. Craig Riddell, and Paul M. Romer. All rights reserved. Short sections of text, not to exceed two paragraphs, may be quoted without explicit permission provided that full credit, including $(C)$ notice, is given to the source. 
Wages, Skills and Technology in the

United States and Canada

Kevin M. Murphy, W. Craig Riddell, and Paul M. Romer

NBER Working Paper No. 6638

July 1998

JEL No. J3, O3

\section{ABSTRACT}

Wages for more- and less-educated workers have followed strikingly different paths in the U.S. and Canada. During the 1980's and 1990's, the ratio of earnings of university graduates to high school graduates increased sharply in the U.S. but fell slightly in Canada.

Katz and Murphy (1992) found that for the U.S. a simple supply-demand model fit the pattern of variation in the premium over time. We find that the same model and parameter estimates explain the variation between the U.S. and Canada. In both instances, the relative demand for moreeducated labor shifts out at the same, consistent rate. Both over time and between countries, the variation in rate of growth of relative wages can be explained by variation in the relative supply of more-educated workers.

Many economists suspect that technological change is causing the steady increases in the relative demand for more-educated labor. If so, these data provide independent evidence on the spatial and temporal variation in the pattern of technological change. Whatever is causing this increased demand for skill, the evidence from Canada suggest that increases in educational attainment and skills can reduce the rate at which relative wages diverge.

Kevin M. Murphy

Graduate School of Business

University of Chicago

1101 East 58th Street

Chicago, IL 60637

and NBER

kevin.murphy@gsb.uchicago.edu

Paul M. Romer

Graduate School of Business

Stanford University

Stanford, CA 93405-5015

and NBER

paul.romer@stanford.edu
W. Craig Riddell

Department of Economics

University of British Columbia

997-1873 East Mall

Vancouver, B.C.

Canada V6T 1Z1 
In this paper, we examine trends in relative wages in the United States and Canada. These trends are of interest for two reasons. First, technological change is likely to affect the distribution of income. The data considered here illustrate some of the consequences we can expect from the introduction of new technologies. They also point in the direction of policy options for dealing with them.

Second, labor market data open up a new window on the process of technological change. As the other papers in this volume suggest, new technologies may arrive at sharply different rates in different decades. There is little doubt that this kind of variation arises at the level of the firm or even at the level of the industry. The interesting conjecture is that it also shows up at the level of the economy as a whole.

The usual way to infer something about variation in the rate of technological change is to use the fact that new technologies raise the first moment of the distribution of income. Variation in the rate of technological change should show up as variation in the rate of growth of average wages, average income, or productivity. However, data on these variables are increasingly suspect because of problems with price mismeasurement that may be getting worse as the economy evolves. (See, for example, Zvi Griliches, 1994.) Errors in measures of the price level will bias measures of real output, real wages, or productivity. Changes in the magnitude of these errors will bias measured rates of growth in these variables. At the same time that we try to construct better price measures, we must also explore other indicators of the trend in technology that are not susceptible to bias from price level mismeasurement.

If, as many people believe, technological change also influences the second moment of the wage distribution, we can use the trend in relative wages as an 
independent indicator of underlying changes in technology. As an alternative indicator, the ratio of two wages has the advantage that it does not require a price index and is therefore invulnerable to bias from price mismeasurement. Of course, this measure has its own disadvantages. For example, relative wages can tell us about the trend in only one component of technological change — the skill bias. Nevertheless, it is a potentially revealing measure that we should certainly exploit, along with others, when we try to understand the evolution of technology over time.

To get at both of the questions that interest us - How does technology influence relative wages? and, How has the rate of technological change varied over time? — we focus in this paper on the university-high school wage premium. We calculate this premium as the ratio of the wage for someone with a university degree to the wage for someone with only a high school education. We illustrate the trends in this premium in Figure 1. This figure presents data from the United States that were explored by Lawrence Katz and Kevin Murphy (1992). We extend this series with illustrative estimates for the United States that extend through 1994. The figure also presents new data for Canada from 1981 to 1994. (Details of the data we use are presented in section 3 below.) For the rest of the analysis presented here, we work with the Katz-Murphy data through 1987 and process the Canadian data in the same way that that they processed their data. For our purposes, the key fact about the data illustrated in Figure 1 is that the university-high school wage premium varies substantially both over time and between countries. In the United States, it grew during the 1960s and fell during the 1970s. Throughout the 1980s, the premium grew in the United States yet fell slightly in Canada. 
Many people have interpreted movements in relative wages as an indicator of the forces influencing the demand for different types of labor. In this sense, they are implicitly adopting the approach that we advocate here — using movements in relative wages as indicators of changes in relative demands (which are in turn related to technological change). However, in informal and popular discussions, people often do not take account of the confounding effects induced by changes in the relative supply of different types of labor. Katz and Murphy (1992) have shown that in the United States, the variation in relative wages plotted in Figure 1 is well explained by a steady growth in relative demand together with the observed changes in relative supply. Changes in relative supply of university and high school educated workers seem to account for the substantial decade-to-decade variations in the path of relative wages illustrated in Figure 1. For the 1980s, we find similar differences in rates of growth of different types of labor between the United States and Canada. As Richard Freeman and Karen Needels (1993) conjectured, supply changes seem to explain the difference in the behavior of the relative wages of more- and less-educated workers in these two countries. Our main result is to show that this qualitative impression carries over to a quantitative representation. The same model that Katz and Murphy used to explain the difference in trends over time in the United States also explains the difference between the trend in inequality between the two countries.

After Katz and Murphy correct for relative supply changes, they find no evidence of variation in the rate at which the relative demand for different types of labor has been shifting over time. After we correct for the effects of changes in supply, we find no evidence of differences in the rate at which the relative demand is shifting in Canada and 
the US. We also find that over the entire sample period the underlying trend seems to have been increasing relative demand at a steady rate. However, within some sub-periods there is some evidence of a slowdown and subsequent speedup relative to the underlying trend. Whether or not this evidence weighs against the hypothesis that the process of technological change has varied in a fundamental way in recent decades is discussed later.

Of course, it is possible that forces such as increased openness to international trade are also shifting the relative demand for labor. It is also possible that the factor bias of technological change (the part of technological change that we measure with relative wages) changes at a steady rate even though the productivity effect of technological change varies from decade to decade. For both of these reasons, one must be cautious in interpreting the meaning of the shifts we infer in the relative demand for labor. The evidence we offer is only one of many different bits of evidence that need to be weighed in making a judgment about overall trends in technological change.

But regardless of how we interpret shifts in the relative demand for labor, it is clear that one cannot infer anything about the magnitude of these shifts, or even their direction, without first correcting for changes in relative supplies of labor. In the data we examine, changes in supply appear to be the most important force causing decade-todecade and country-to-country variation in trends in relative wages. If this relationship holds more generally, it has important implications for policy responses to growing wage inequality caused by technological change. Policy makers who want to influence relative wages may find it easier and more productive to adjust the relative supply of workers with different levels of education than the relative demand. If the government adopts 
policies which raise educational attainment of some workers, it simultaneously increases the relative supply of more educated workers and lowers the relative supply of less educated workers. Educational subsidies can therefore have a doubly powerful effect on the relative supply. We find a relatively high degree of substitution between different types of workers. Nevertheless, feasible changes in government policies — changes that are of the same magnitude as the differences in policies we see between the United States and Canada - can have a substantial effect on the wage premium, and therefore on income inequality. Moreover, other kinds of policies to encourage skill formation are likely to have the same effect.

In the next section, we relate our results to work from labor economics, economic history, and growth theory. We also outline some of the main positions in the old political debate about economic prospects for workers in the bottom part of the income distribution. Then we present our basic model and describe our data and results. We conclude with some conjectures about how to reconcile our wage-based finding of no change in the process of technological change with the usual quantity-based finding of a substantial productivity slowdown in the 1970s.

\section{Technological change, income inequality, and policy}

Although few economists stress the connection, the assumption that new technologies (or new types of capital goods) are relative complements with more educated labor is closely related to the popular intuition that machinery and new technology harm low-skill workers. This concern forms the basis for one side in the longstanding debate about the connection between technology, growth and income inequality, a debate that goes back at least to Ricardo's discussion of machinery. 
In this debate, proponents of what one could call the "interventionist" position start from the presumption that technological change harms workers in the bottom part of the income distribution. They conclude that the gains from economic growth will be widely shared only if governments adopt activist policies that resist market forces. Examples of such policies include a minimum wage, regulations limiting work hours, unemployment insurance, workers' compensation, employment standards, and support for unions that negotiate above market wages. Proponents of the interventionist position believe that the advanced industrial economies have been able to achieve a relatively equal sharing of the gains from growth only because governments adopted these measures. Many of them fear that a process of global competition will lead to an erosion of these interventions and a corresponding growth in income inequality.

An opposing pole in this debate comes from within the economics profession. Economists do not necessarily oppose the kinds of social welfare policies advocated by the interventionists. Some do, and some do not. However, they are close to unanimous that these measures by themselves cannot explain much of the gains in standards of living experienced by people in the bottom half of the income distribution. The economists argue that technological change and the market forces it unleashes tend naturally to raise the incomes of all members of the labor force, just as the proverbial rising tide lifts all boats. According to this view, wages for all types of workers will naturally tend to grow as technological change raises the average level of income.

Paul Samuelson's principles textbook gives a representative statement of this rising-tide position as of the mid-1960s: 
An alternative theory would ascribe the rise of wages under capitalism to (1) trade-union pressure, (2) government regulation of monopoly, and (3) interventions of a welfare and regulatory kind by democratic governments reacting to militant political pressures from the masses. This cannot be rejected as without substance, for we have seen throughout this book that government actions do have consequences for both good and evil. But the magnitude and pattern of the rise in real wages in this last century has been such as to cast doubt on union or political action as an important element in its explanation. ... With the advance of technology and the piling up of a larger stock of capital goods, it would take a veritable miracle of the devil to keep real wages of men from being bid ever higher with each passing decade. Who fails to see this fails to understand the fundamentals of economic history, as it actually happened. (Samuelson, 1964, p. 773)

Samuelson is surely correct when he argues that supporters of the interventionist position are wrong about the reasons why income gains have been widely shared since the beginning of the industrial revolution. However, his explanation in terms of capital accumulation and technological change fails to confront the microeconomic evidence suggesting that everything else equal, technological progress can harm large parts of the labor force even as it helps others.

The neoclassical vision that Samuelson articulates, one based on the assumption that technology is a complement with a homogeneous labor aggregate, has dominated textbook and policy discussions of wage trends for many years. Economists formalized this view in the neoclassical growth model based on two factors of production: capital and labor. It continues to be embedded in most treatments of aggregate growth. Even growth models that explicitly introduce human capital as a separate factor of production generally do so in a way that makes more educated workers perfect substitutes with less 
educated workers (Assaf Razin, 1972; Robert Lucas, 1988) or that makes technology a complement with both types of labor (N. Gregory Mankiw, David Romer and David Weil, 1992; Paul Romer, 1990). Either way, there is no scope in such models for technological change to differentially affect wages for workers with different levels of education. In particular, there is no recognition that technological change can reduce wages for some workers.

However, there are two important lines of work in economics that do treat different types of labor as inputs that could be differentially affected by technological progress or capital accumulation. Since the work of Sherwin Rosen (1968) and Griliches (1969), a number of labor economists have presented evidence supporting the notion that higher skilled or more educated workers benefit disproportionately from capital investment or technological change. The evidence is sketchy, but tends to suggest that more educated workers are stronger complements with new investment than less educated workers. It also suggests that there is a relatively high degree of substitution between these two types of workers. (See Daniel Hamermesh, 1993, for a summary of research on these questions.)

These conclusions are reinforced by the work of economic historians on education and wages. In the last century, the level of educational attainment in the population has increased substantially. (See, for example, the discussion of the experience in the US presented by Claudia Goldin, 1994.) In the absence of some force that increases the relative demand for educated labor, this increase in the relative supply of more educated workers should have driven their relative wage inexorably downward if more educated workers are not perfect substitutes with less educated workers. 
Both the historical evidence (e.g., Katz and Goldin, 1995) and the contemporary evidence from labor markets (Hamermesh, 1992; Katz and Murphy, 1992) suggest that relative wages for more educated workers do fall when the supply of educated workers outpaces growth in demand. This evidence and everyday experience both suggest that workers with different levels of education are not perfect substitutes. Four workers with six years of education cannot do the job that one worker with 24 years of education can do. Adding more workers with a primary education to the task usually will not help. The elasticity of substitution between more- and less-educated workers is large, but it is not infinite. They are substitutes, but they are not perfect substitutes.

Nevertheless, the general historical pattern is one with no persistent tendency for relative wages of more educated workers to fall despite the large increases in their relative supply. For more than a century, some force must therefore have been increasing the relative demand for more educated workers.

Some economists have pointed to increased international trade as the source of the demand shifts that have taken place in the last couple of decades. (Edward Leamer, 1996; Adrian Wood, 1994). Most attempts at quantifying the effects of trade fall far short of explaining the shifts (Jeffrey Sachs and Howard Shatz, 1994) or find other evidence that is inconsistent with the trade explanation (Katz and Murphy, 1992; Robert Lawrence and Matthew Slaughter, 1993). Nevertheless, the interpretation of the shifts remains open because it is difficult to offer direct evidence on the effects of technological change. (However, see, for example, Frank Levy and Richard Murnane, 1996.) The historical evidence is relevant because it reminds us that the pattern of relative demand shifts extends back at least into the last century. Any explanation based on developments in the 
world trading system since World War II cannot capture the whole story. It also fails to explain why levels of education have been growing throughout the world without driving down the worldwide returns to education.

Technological change is an obvious candidate force that has been impinging on the economy for centuries. There is no theoretical presumption that technological change will always tend to raise the demand for more educated workers. Nevertheless, the evidence suggests that over long historical periods, it has done so.

In their analysis of historical trends, the proponents of the interventionist interpretation overestimate the power of conventional labor market policies. They also fail to appreciate the overwhelming importance of education as a force that limits the growth in inequality. But in responding to the interventionists, the proponents of the rising-tide view tend to oversimplify, perhaps even overstate, their case. They gloss over both the theory and the evidence suggesting that technological change can depress both relative and absolute wages for workers in the bottom part of the skill or educational distribution. Like the interventionists, advocates for the rising-tide model also fail to emphasize the importance of increases in educational attainment.

In language that they borrow from Jan Tinbergen (1975), Katz and Goldin (1996) suggest that it is more appropriate to think of the behavior of the relative wage of the skilled and unskilled as the outcome of a race between technological change and increases in educational attainment. The theory and evidence that we present here fits more comfortably with this education-race view than it does with either the interventionist or rising-tide explanations for the interaction between growth and inequality. 
In recent years, the various positions in the debate about wages and technology have become more complicated than these three positions suggest. The growth in wage inequality in the United States during the 1980s made it increasingly difficult to support a pure version of the rising-tide position on growth and wages. As a result, a variety of economists began to consider once again the possibility that technological change could increase inequality. Because they believe that the rising-tide theory fits the historical facts, they suggest that something fundamental about the nature of technology must have changed. This re-examination has lent additional importance to the concept of a "general purpose technology" or GPT that was defined by Timothy Bresnahan and Manuel Trajtenberg (1995) and analyzed in the context of a model of growth by Elhanan Helpman and Trajtenberg (1994). The introduction of a new general-purpose technology is a natural way to explain a sharp change in the nature and consequences of technological change.

In economic history in general and especially in discussions of technology, there are many antecedents for the concept of a general purpose technology (GPT). For example, it is closely related to the concept of "technological convergence" as described by Nathan Rosenberg (1963) in his discussion of the central role that machine tools played in the development of industry in the last century. It can also be understood as a refinement and formalization of the concept of a technological trajectory as described by Christopher Freeman and Carlota Perez (1988).

As it has come to be used, both in this volume and more generally, the concept of a GPT captures two distinct ideas. First, it formalizes the notion that technological change is an irregular process that can have different effects on the economy at different 
times. Second, the concept of a GPT reminds us that adopting new technologies can be costly and disruptive. In this sense, it echoes and partially rehabilitates the old Ricardian and Marxian vision of technology as a double-edged sword.

This first part of the GPT concept - the claim that technological change can be radically different in different periods — offers one possible reason why technological change seemed to have different effects in the 1950s and 1960s as opposed to the 1970s and 1980s. This leads to the fourth and final theoretical position that we identify concerning the relationship between growth and inequality. The "trend-break" hypothesis argues that developments in the last two decades represent an important departure from the rest of the post-WWII period. According to the most common statement of this view, the digital computer is the natural candidate for a GPT that began working its way through the economy in the last two decades. Some economists have argued that this approach offers a unified explanation for both the productivity slowdown and the increase in wage inequality (Jeremy Greenwood and Mehmet Yorukoglu, 1997). Others recognize that it is difficult to explain the difference in the timing of these events with a single technology shock. The productivity slowdown in the United States was evident in the data even before the oil shock in the early 1970s. Wage inequality did not begin to increase until the end of the 1970s. As a result, other proponents of the trend-break view have used the arrival of the computer to explain just the productivity slowdown (Paul David, 1991) or just the developments in the labor market (Alan Krueger, 1993).

There are many possible versions of the trend-break position and combinations of this position with the other positions outlined here. For example, the economy could cycle back and forth. In periods when a new GPT is being introduced, productivity 
growth slows and income inequality could increase. In periods when existing GPTs are being developed, productivity growth could be more rapid and income inequality could shrink. Yet over long periods of time, the average behavior of the economy could look like one characterized by the rising-tide model (Helpman and Trajtenberg, 1994). Alternatively, the trend break could be imposed on top of a model of an education race, as suggested by David Autor, Katz, and Krueger (1997).

In this broader context, we can restate our conclusions. Based on the behavior of wages in the United States and Canada, we see no reason to prefer a trend-break model to a pure model of an education race with a constant rate of technological change. The education race model seems to fit the historical data and our evidence on developments over the last few decades and between the US and Canada. In this sense, our evidence does not provide any aggregate level support for the first of the two ideas subsumed in the concept of the GPT — the idea that there are sharp breaks in the process of technological change. This does not deny the importance of irregularity or trend breaks in the analysis of technological change at the microeconomic level or in the analysis of specific technologies like digital computing. It merely suggests that their effects may average out if there are enough different technologies following independent trajectories. At the aggregate level, the process may resemble most closely a steady process of technological change.

Although a steady rate of technological advance does appear to fit best with our Canadian and U.S. evidence over the entire sample period, we do find some evidence of a slowdown and speedup phenomenon during relatively brief sub-periods of the U.S. 
experience. As we note later, this evidence appears consistent with some theoretical predictions of the economy-wide impacts of GPTs.

In developing this position, we are forced to move well outside the framework of a simple neoclassical model in which one can treat labor as a homogeneous commodity or treat all factors of production as complements with technology. We allow skilled labor and unskilled labor to be substitutes for each other and take seriously the possibility that technological change can reduce the relative or absolute wage for low skilled workers. It has long been clear that it is theoretically possible for Ricardo's fears to be realized. (See for example, Samuelson, 1988.) The evidence from the labor market that we examine supports Ricardo's concerns about machinery, or, more precisely, it supports a closely related concern about technology. It suggests that this concern is of real significance in practice, not just in principle.

In this sense, we support and extend the revisionist interpretation of technological change that is implicit in the concept of a GPT. In the neo-classical growth model and simple endogenous growth models, technological advance tends to raise the marginal productivity of all factors of production, and growth proceeds in a smooth fashion by scaling up the marginal productivity of all factors of production. The new interpretation implicit in the concept of a GPT is that new technologies cause large changes in the relative marginal productivity of different inputs. These changes in relative returns induce large changes in prices and offsetting changes in patterns of investment throughout the economy. Our interpretation of the evidence in terms of an education race is fully consistent with this second thread in the concept of a general purpose technology. 


\section{Model}

The basic model that we use to motivate our analysis starts with a constant elasticity of substitution aggregator that depends on university-educated labor, $H$, and high school-educated labor, $L$. Because we are interested in the effects of technological change, not its sources, we will represent technological change in terms of exogenous functions of time. Specifically, we characterize technological change in terms of two functions of time, $A(t)$ and $B(t)$. The first augments the services of university-educated workers; the second augments high school-educated workers. Then we nest the expression for labor inside a Cobb-Douglas function that depends on this labor aggregate and physical capital, $K$ :

$$
\begin{aligned}
Y & =F(K, H, L, t) \\
& =K^{\alpha}\left(\gamma(A(t) H)^{\frac{\sigma-1}{\sigma}}+(1-\gamma)(B(t) L)^{\frac{\sigma-1}{\sigma}}\right)^{\frac{(1-\alpha) \sigma}{\sigma-1}}
\end{aligned}
$$

When we use this kind of single-sector, aggregate production function, we must be clear about what it means. At time $t, F(K, H, L, t)$ represents the maximum possible output for an economy with total resources $K, H$, and $L$. This kind of aggregate production function is always well defined. However, there is no reason to believe that actual economies satisfy the assumptions from aggregation theory necessary for us to be able to give this aggregate production any simple interpretation in terms of the production functions of individual firms.

For example, the parameter $\sigma$, which controls the elasticity of substitution between $H$ and $L$ in the aggregate economy, may not be closely related to the elasticity 
of substitution faced by an individual firm. Shifts between firms or industries may be more important than shifts within firms. Similarly, one cannot necessarily interpret the aggregate augmentation factors $A(t)$ and $B(t)$ in terms of standard microeconomic processes of technological change. At the firm level, one would typically impose the restriction that technological factors that augment inputs like $H$ and $L$ are monotonically nondecreasing. In general, this kind of microeconomic assumption does not imply anything about the behavior of the aggregate functions $A(t)$ and $B(t)$.

We make one final observation. When we apply this model to data from the last four decades, we will interpret more educated workers $H$ as workers with a university degree and less educated workers $L$ as workers with a high school education. However, if we wanted to apply the model to earlier historical periods, we would bring in additional levels of education. What constitutes a less skilled worker changes over time. For example, if we let $M$ denote workers with only a primary school education, we could write an extended production function $\hat{F}$ as follows:

$$
\begin{aligned}
& \hat{F}(K, H, L, M, t)= \\
& \quad K^{\alpha}\left(\gamma(A(t) H)^{\frac{\sigma-1}{\sigma}}+\varphi(B(t) L)^{\frac{\sigma-1}{\sigma}}+(1-\gamma-\varphi)(D(t) M)^{\frac{\sigma-1}{\sigma}}\right)^{\frac{(1-\alpha) \sigma}{\sigma-1}}
\end{aligned}
$$

In the decades from the 1960s to the 1990s, a period of time when university graduates became a significant fraction of the labor force, changes in the economy made the factor $A(t)$ grow relatively rapidly and made the factor $B(t)$ grow slowly or shrink. The number of workers with primary education $M$ was sufficiently small that the dominant group in the "less educated" workers is those with high school education. However, at the turn of the century, an insignificant fraction of the labor force was 
university educated. Relatively few workers were high school educated, and they were relatively more educated compared to workers with only a primary school education. At that time, changes in the economy were leading to a greater demand for high school workers. In terms of the model, $B(t)$ was growing rapidly compared to $A(t)$ and $D(t)$. (See Goldin 1994, Goldin and Katz, 1995, 1996 for a description of the changes that were taking place.) Thus, whether a high school-educated worker is a relatively high-skilled or a relatively low-skilled worker depends very much on the epoch one considers.

If we neglect the primary-educated workers and return to our basic equation (1), we can solve for the ratio of the marginal products of the two types of labor:

$$
\frac{W_{H}}{W_{L}}=C\left(\frac{A(t)}{B(t)}\right)^{\frac{\sigma-1}{\sigma}}\left(\frac{H}{L}\right)^{-\frac{1}{\sigma}}
$$

where $C$ is a constant. We can define growth rate functions $g_{A}(t)$ and $g_{B}(t)$ by the rules

$$
g_{A}(t)=\ln (A(t)), \quad g_{B}(t)=\ln (B(t))
$$

Then we can take logarithms in equation (2) and write

$$
\ln \left(\frac{W_{H}}{W_{L}}(t)\right)=c+\frac{\sigma-1}{\sigma}\left(g_{A}(t)-g_{B}(t)\right)-\frac{1}{\sigma} \ln \left(\frac{H}{L}\right) .
$$

This is the equation that we will confront with the data. We will be interested in the hypothesis that the data are consistent with a model in which the difference $g(t)=g_{A}(t)-g_{B}(t)$ grows linearly with time. If they are, we can write equation 3 as

$$
\ln \left(\frac{W_{H}}{W_{L}}(t)\right)=c+\frac{\sigma-1}{\sigma} g t-\frac{1}{\sigma} \ln \left(\frac{H}{L}\right)
$$

for some constant $g$. If this restriction holds, we can also write this relation in difference form: 


$$
\Delta \%\left(\frac{W_{H}}{W_{L}}(t)\right)=\frac{\sigma-1}{\sigma} g-\frac{1}{\sigma} \Delta \%\left(\frac{H}{L}(t)\right),
$$

where $\Delta \% X$ stands for the percentage change in $X$.

\section{Data}

\section{United States}

Except for the illustrative data used in Figure 1, the data for the United States are the same as those used in Katz and Murphy (1992), so our description will be relatively brief. We describe the details primarily to illustrate the steps we will take with the Canadian data. Raw data from the US come from the March Current Population Survey covering data for years from 1963 to 1987 . Katz and Murphy use two different samples to construct the wage and labor supply series. The preferred wage series tracks as closely as possible the wage for a homogenous group of workers, so the sample is restricted to people with strong labor market attachment. For labor supply, they use a much broader sample that reflects total hours, by education category, actually worked in the economy in each year. The labor supply series include hours worked for essentially all people in the CPS.

The wage series for high school graduates is based on wages for people with 12 years of schooling. The series for university graduates is based on wages for people who report having 16 or more years of schooling. After eliminating people who participated in the labor force less than 39 weeks in the year prior to the March survey, Katz and Murphy classify workers by sex ( 2 cells) and years of experience ( 8 cells). In each of these 16 cells, they calculate an average wage for each year, then form a wage for all high school graduates (or all university graduates) by taking a weighted average of wages in 
the different cells. The weights are based on the fraction of total hours worked by all individuals in the cell, averaged over all years in the sample. Because the weights do not change over time, both the high school and university wage series give an estimate of the average wage for a pool of workers with fixed demographic characteristics.

To construct the labor supply series, they count hours worked for all workers and classify them into four categories based on educational attainment: less than 12 years, 12 years, 13-15 years, and 16 or more years of schooling. Labor supply in each of these four categories is calculated by assuming that workers within these categories are perfect substitutes and summing up total hours worked using efficiency units based on average wages for each sex and experience cell.

In the final stage, they aggregate hours worked for these four educational categories into two series corresponding to hours of work by high school-equivalent workers and hours worked by university-equivalent workers. Because we do not want to assume that workers with different levels of education are perfect substitutes, we have to be careful not to use the wrong procedure to do this aggregation. For example, if we followed an efficiency units approach, we could assume that a worker with 14 years of education is a more efficient provider of the kind of labor provided by high school graduates, and use the ratio of wages for these workers to high school-educated workers to find the scaling factor. Or we could assume that this worker is a less efficient provider of the kind of labor provided by university graduates, and use the ratio of their wages to wages for university graduates to calculate efficiency units for them.

To establish the basic units of measurement, assume that in the United States, individuals with 12 years of education supply, on average, one hour of high school- 
equivalent labor per hour worked. Similarly, assume that someone with 16 or more years of education supplies one hour of university-equivalent labor per hour worked. To deal with the other two categories, Katz and Murphy assumed that someone in educational category $i$ supplied $a_{i}$ hours, measured in efficiency units, of high school-equivalent labor per hour worked and $b_{i}$ hours, measured in efficiency units, of universityequivalent labor per hour worked. They estimate the coefficients $a_{i}$ and $b_{i}$ by running a regression (with no constant term) of the wage series for people in education category $i$ on wages for high school workers and university educated workers:

$$
w_{i}=a_{i} w_{L}+b_{i} w_{H}
$$

In this expression, $w_{L}$ and $w_{H}$ represent the wage series for the high school- and university-educated workers respectively.

\section{Canada}

There are a number of arbitrary choices one must make in constructing aggregate relative wage and relative supply series. There are valid rationales for different choices and none of these choices seem to make an important difference to our final results. Our goal in processing the data for Canada was simply to follow as closely as possible the treatment that Katz and Murphy used for the data in the United States. However, because the measurement of educational attainment in the Canadian survey differs from that in the United States and because the Canadian data are available for fewer years, the exact procedures we followed differ slightly.

The data for Canada come from the Survey of Consumer Finances (SCF), an annual supplement to the Labour Force Survey carried out in April of each year. This 
annual supplement is very similar to the March CPS. Indeed, these two surveys have been used in other comparisons of the Canadian and US labor markets. (See for example, the articles in Card and Freeman, 1993.) The SCF has data on all individuals 15 years of age and older starting only in 1981. Before that year, hours worked are publicly available only for heads-of-households, yet reported income is for the entire household. In addition, this survey did not collect data for 1983 . Thus, our sample includes the 13 years 1981-82 and 1984-94.

The SCF does not report years of education. Instead it reports 5 categories of educational attainment: (1) attended primary school, (2) some high school, (3) some postsecondary, (4) diploma or certificate from a community college, (5) a university degree. Throughout this paper, we follow the Canadian usage and distinguish between a university degree and a college diploma or certificate. A college diploma or certificate typically requires 2 years whereas a university degree generally requires 3 or 4 years. (Because students in the province of Ontario typically continue in high school through grade 13, they may complete the course of study in what one would consider a 4-year institution in only 3 years.) We treat the average worker with some high school as the basic unit for high school equivalent labor in Canada. Note that this is a different unit from the one used in the United States, 12 years of schooling. We allow for a correction factor that takes account of this and any other stable differences between the US and Canada. Naturally, we treat the average worker with a university degree as the unit for measuring hours worked by university-educated workers.

As for the data from the US, we use the survey information on earnings and weeks of work during the previous year rather than the month of the survey. Because the 
SCF does not ask about usual hours worked in the previous year, we simply use weeks worked instead of total hours as our labor supply measure. The CPS does ask this question so labor supply for the US is measured in hours worked. For Canada, we discarded any records with non-positive earnings or weeks worked. We formed an estimate of total labor supply using a sample that includes everyone with positive weeks worked. Following the Katz-Murphy treatment of the US data, we formed a separate sample to estimate the weekly wages (annual earnings divided by weeks worked). In the wage sample, we included full time, paid workers with 39 or more weeks in the labor force and who earned at least one half of the full-year, full-time minimum wage earnings during the year.

We formed cells based on the five educational attainment categories described above, eight experience categories, and the two sexes. Because the survey gives educational attainment by broad category rather than by years of education completed, we subtracted the average years associated with a given level of attainment from age to form an estimate of years of experience in the labor market for workers in each educational category.

The SCF made a major change in the educational attainment questions which affect the years 1989 and after. Although the education questions were much improved, the pre-1989 and post-1989 data are not comparable. At present, no parallel survey for estimating independent conversion factors is available. We adjusted the data by fitting a trend and a post-1989 dummy to each time series. We adjusted the post-1989 data by the value of the coefficient on the post 1989 dummy. These adjustments do not make much difference for the real weekly wage series but do matter for the weeks worked series. If 
more data becomes available, it would be useful to improve on this crude adjustment procedure.

The final step is to aggregate our five labor supply series to two series of labor supply measured in units of high school equivalents and university equivalents. As noted above, we treated people in the some-high-school category as our reference level for measuring high school equivalents. That is, we assumed that the average Canadian worker in the some-high-school category supplied one hour of Canadian high-school equivalent labor per hour worked. One Canadian high-school equivalent hour will differ from one US high-school equivalent hour because we defined high school equivalent workers in the US in terms of people with 12 years of education. If there are any differences in the quality of the Canadian and US educational systems, this will also lead to a difference in the two concepts of hours of high-school labor supplied in the two countries. Finally, labor supply in Canada is in weeks worked. In the US it is hours worked.

We make an allowance for these differences when we compare the two countries. We can do this because all of our estimates depend only on the rate of growth of $H / L$, not on its level. In principle, it is possible that a university education has a different market value in the two countries. Our adjustment allows for this possibility as well, provided the difference in quality does not change over time.

Table 1 reports the fraction of total weeks worked that are accounted for by each of the five different education categories in Canada. These fractions are based on averages taken over all 13 years for which we have data in the 14 years from 1981 to 1994. It also reports the rates of growth of total weeks supplied by people in each of these 
categories. Workers with college diplomas or certificates supply slightly more labor than university graduates and their labor supply grows as rapidly as the labor supply of university graduates.

\begin{tabular}{|c|c|c|c|c|c|}
\hline & $\begin{array}{c}\text { Primary } \\
\text { school }\end{array}$ & $\begin{array}{c}\text { Some } \\
\text { high } \\
\text { school }\end{array}$ & $\begin{array}{c}\text { Some post- } \\
\text { secondary }\end{array}$ & $\begin{array}{c}\text { College } \\
\text { graduates }\end{array}$ & $\begin{array}{c}\text { University } \\
\text { graduates }\end{array}$ \\
\hline $\begin{array}{c}\text { Fraction of total } \\
\text { weeks worked }\end{array}$ & $7 \%$ & $47 \%$ & $10 \%$ & $18 \%$ & $17 \%$ \\
\hline $\begin{array}{c}\text { Growth rate of } \\
\text { weeks worked }\end{array}$ & $-5.3 \%$ & $-0.1 \%$ & $2.4 \%$ & $5.3 \%$ & $5.2 \%$ \\
\hline
\end{tabular}

Table 1: Summary statistics on weeks worked by educational category in Canada

Our final challenge is to allocate weeks worked by people in the three remaining educational categories: primary school, some post-secondary schooling, and college graduate. As before, we assume that on average, a worker in category $i$ supplies a fixed number $a_{i}$ of efficiency units of high school-equivalent hours per week worked and a fixed number $b_{i}$ of efficiency units of university-equivalent labor per week worked.

We have only 13 annual observations on wages for each of the five educational attainment categories. In addition, wages in Canada do not exhibit the kind of sharp movements that we see in the United States in the Katz-Murphy sample. For both of these reasons, any attempt to use a regression to estimate the coefficients in an equation like (6) is unlikely to yield very precise estimates. As a result, we tried a variety of different estimates for $a_{i}$ and $b_{i}$ and found that our conclusions were not sensitive to the values we used.

Workers who have completed a primary school education are relatively easy to handle. In both countries, wages of primary school-educated workers are little different from wages for people in some-high-school or 12-year categories. In Canada, they earn 
about $98 \%$ of the wages for the workers with some high school. In the United States, workers with less than 12 years of education earn about $94 \%$ of the wages earned by workers with 12 years of education. In each country, we allocated $95 \%$ of the labor supply of workers in the lowest skill category to labor supply for high school equivalents and allocated none of their labor to university equivalents:

$$
a_{\text {primary }}=\frac{\text { average } W_{\text {primary }}}{\text { average } W_{\text {some high school }}}=0.95, \quad b_{\text {primary }}=0 .
$$

These are very close to the weights of .94 and -.04 used by Katz and Murphy. They used weights of .69 and .29 to allocate work effort by workers with some postsecondary education to high school equivalents and university equivalents respectively. Because we could not estimate these weights for the some post secondary and college diploma categories in Canada, we followed the lead of Autor, Katz, and Krueger (1997). In one of their estimates, they set both of the weights $a_{i}$ and $b_{i}$ for workers with education beyond high school equal to 0.5 . Like them, we allocated one half of the weeks worked by workers with some post-secondary education to high school equivalents and one half to university equivalents. We used these same values for people with a college education.

Figure 2 illustrates the small difference that it makes when we change the weights for the United States from the ones estimated by Katz and Murphy to the more arbitrary ones we used in both samples in our analysis. It plots both the logarithm of the actual university-high school relative wage and the predictions generated by the two different labor supply series. One series uses the Katz-Murphy weights and replicates their regression: 


$$
\ln \left(\frac{w_{H}}{w_{L}}\right)=\text { constant }-.71 \ln \left(\frac{H}{L}\right)+\underset{(.007)}{.033} t, R^{2}=.52
$$

Standard errors are reported below the coefficient estimates. The relative supply series with the new weights generates slightly different coefficient estimates

$$
\ln \left(\frac{w_{H}}{w_{L}}\right)=\text { constant }-.81 \ln \left(\frac{H}{L}\right)+\underset{(.007)}{.035} t, R^{2}=.53
$$

As the figure shows, these two equations and relative supply series generate very similar predictions for the relative wage. We also checked that our conclusions remain the same if we use the Katz-Murphy weights for both countries instead of the weights described here.

\section{Estimation and Results}

Figure 3 illustrates the sense in which we need to impose some restriction on the behavior of $g(t)$ over time to be able to pin down the elasticity $\sigma$. If we take equation (3) and solve for $g(t)$ we have

$$
g(t)=\frac{\sigma}{\sigma-1}\left\{\ln \left(\frac{w_{H}}{w_{L}}(t)\right)+\frac{1}{\sigma} \ln \left(\frac{H}{L}(t)\right)-c\right\} .
$$

Given a value for $\sigma$, we can calculate the time path for $g(t)$ up to a constant term, which is of no interest. The figure plots the values of $g(t)$ calculated in this way for different values of $\sigma$ and for both the United States and Canada. In their analysis of data for the United States, Katz and Murphy found a value of $\sigma$ equal to 1.41. Thus, in this figure, we plot data for $\sigma$ equal to $1.25,1.5$, and 2 . We have adjusted the vertical position of the curves to make the graph more readable. The vertical position carries no information. 
Only the slope matters. In addition to the data series, the figure also plots trend lines calculated from a linear regression of $g(t)$ on time.

If, based on a priori information, one specified that $g(t)$ follows precisely the time path associated with one of the values of $\sigma$, then inference conditional on this path for $g(t)$ would select precisely this value of $\sigma$. In this sense, we cannot identify $\sigma$ without imposing some restriction on the behavior of $g(t)$. There is a one-dimensional continuum of values for $\sigma$ and paths for $g(t)$ that will fit the data exactly. Thus, for every possible value of $\sigma$, there is a path for $g(t)$ that would rationalize this value. However, the converse is not true. Because the set of possible paths is much larger than the onedimensional set of possible values for $\sigma$, we generally will not be able to find a value for $\sigma$ that will make an arbitrary path consistent with the data. Thus we can test and reject hypotheses about the behavior of $g(t)$.

Figure 3 also illustrates one of the basic messages from our analysis. In this figure, we have not imposed any restriction that forces the slopes of the trend lines to be the same in Canada and the US for each value of $\sigma$. Nevertheless, these slopes are very close. Also, for all of the illustrated values of $\sigma$, the path for $g(t)$ fits a straight line surprisingly well. The one exception, to which we will return below, arises when $g(t)$ seems to grow more slowly starting in about 1976 and then grows faster and recovers back to the trend line starting in 1982.

Figure 4 shows what happens if we impose the restriction that $g(t)$ is equal to $g t$ and then estimate the parameters $\sigma$ and $g$. This figure plots the actual and predicted values of the relative wage in the United States and Canada along with the predicted 
values from the regression. (To improve readability, note that the values for Canada are plotted against a scale that is translated vertically downward.) The regression estimates behind this equation are

$$
\ln \left(\frac{w_{H}}{w_{L}}\right)=c_{\mathrm{US}}+c_{\text {Canada }}-.73 \ln \left(\frac{H}{L}\right)+\underset{(.13)}{.032} t, R^{2}=.56
$$

We also performed a Chow test to see whether the Canadian and U.S. parameters differ. The F statistic for testing the null hypothesis that slope and trend coefficients are the same is $F_{2,33}=1.2$. If we impose the Katz-Murphy weights on both countries, the corresponding statistic is $\mathrm{F}_{2,33}=1.4$. In either case, we cannot reject the hypothesis that the coefficients are the same.

In this equation, we have allowed for separate constant terms for Canada and the US. To account for the differences between the data for the two countries, we assume that the true value of $H / L$ in one country, measured in terms of the definitions from the other country, differs from our estimate by a constant factor. When we take logarithms of the relative supply, this factor will be captured in the different values for the constant term. These will pick up any systematic differences between the measured variables in the two countries.

Equation 5, which we repeat below, helps us illustrate why the data imposes some restrictions on the trend process even though $\sigma$ is not, strictly speaking, identified.

$$
\Delta \%\left(\frac{W_{H}}{W_{L}}(t)\right)=\frac{\sigma-1}{\sigma} g-\frac{1}{\sigma} \Delta \%\left(\frac{H}{L}(t)\right)
$$


Roughly speaking, we ask whether the data are consistent with the restriction imposed by this equation, and test it against the alternative that the trend rate of growth $g$ takes on different values in the first and second halves of the sample.

Figure 5 gives an alternative representation of the data represented in Figure 2, a representation that is suggested by equation 5 . This figure collapses the data into three key periods in the US data and adds a fourth data point for Canada. The three periods in the US were determined by picking the turning points in the predicted relative wage series in Figure 4. After aggregating the data into these four points, we can put them on the scatter diagram suggested by equation 5 . According to this equation, these points should fit on a straight line with slope $-1 / \%$ and should have an intercept $g$. As Figure 2 suggests, the data are roughly consistent with this characterization. We could also fit these four points with four different lines that have the same slope and four different intercepts. These intercepts will correspond to the implied values for $g$ in each period. However, as Figure 5 shows, we will not be able to do so in a way that makes $g$ consistently different in the first and second halves of the sample. For example, if we make the slope of the line flatter by making $\sigma$ larger, it will impose a relatively high value of $g$ in the 1960s and 1980s in the US and a relatively low value for $g$ in the 1970s in the US and in the 1980s in Canada.

If we want to conduct a formal test for a break in the trend, we face the problem of picking the point where we split the sample and the more difficult problem of interpreting the results. Figure 6 represents the results from a series of t-tests for a change in the value of $\mathrm{g}$. For each point in the bottom curve in the graph, we estimated a separate regression with a dummy variable interacted with the trend term. In each of 
these regressions, the dummy allows for a break in a different year. We ran these tests for all years from 1968 to 1987 . Each point on this bottom curve corresponds to the estimate of this term. It can be interpreted as the change in the value of $g$ for all years after the date corresponding to the point. The points that have a t-statistic that is less than 2 are marked with triangles and connected with lines. The points with a t statistic greater than 2 are marked with squares and are not connected with lines.

From this figure, we can infer that a test for a trend break starting in 1974 to 1977 would find a statistically significant slowdown in the rate at which the relative demand for more educated labor has been growing. In contrast, a test in the years 1981 to 1985 would find a statistically significant increase in the rate at which the relative demand is increasing. This slowdown and speedup are parallel to the slowdown and speedup in the paths for $g(t)$ that we observed in Figure 3. By comparing the predicted and actual values for the real wage, one can see in Figure 6 another manifestation of this same process. Between about 1976 and 1981, the changes in relative supplies imply a higher value of the relative wage than the actual value. The estimated trend breaks are another manifestation of the fact that the regression estimates over-predict wages during this period. If we estimate a coefficient for a slowdown in $g$ in 1976 and a speedup in 1981, both of these coefficients are statistically significant. In 1981, the rate returns back to its previous value, as Figure 3 suggests. This formulation with both a slowdown and a speedup best captures the behavior of the data. Although it is not clear that we should interpret this as evidence of a trend-break, this type of slowdown and speedup phenomenon may be consistent with some theoretical predictions of the impacts of GPTs, such as those in the model developed by Helpman and Trajtenberg (1994). 


\section{Conclusions}

There are two ways to interpret the inconsistency between our results and direct productivity measures, which find a significant slowdown after the early 1970s. In the first interpretation, the direct productivity measures are telling us that the rate of growth of the functions $A(t)$ and $B(t)$ has decreased since the 1970s; the labor market evidence is telling us that the rate of growth of the difference $A(t)-B(t)$ does not seem to have changed. That is, productivity growth has slowed down but the rate of increase in the skill bias in technology has not. In the second interpretation, the rate of growth has not changed for either $A(t)$ or $B(t)$. This explains the labor market evidence which points to no break in the factor bias of technology. The evidence of a productivity slowdown must therefore be the result of price mismeasurement that has been getting steadily worse over time. Our results by themselves offer no basis for choosing between these two explanations. However, until a few years ago, the second possibility was given little serious consideration in the economics profession. We interpret our results as one additional bit of evidence suggesting that this second interpretation deserves careful consideration. We need to convert the productivity slowdown from a fact about the economy that needs to be explained into a hypothesis about the economy that needs to be more fully investigated.

Regardless of which of these interpretations is correct, the evidence provided here offers additional support for the claim that over time, the cumulative effect of technological change has been to increase the relative demand for more educated workers. The evidence presented here also suggests that the relative earnings of moreand less-educated workers respond to changes in their relative supply, i.e. that labor 
demand is sensitive to the price of labor. Because they can influence the relative supply of more and less educated workers, governments control powerful policies for counteracting this unwanted side effect of technological progress. Policies like those followed in Canada - policies that facilitated during the past two decades substantial growth in post-secondary education at both the college and university levels - can have a major effect on wage inequality. Our results imply that in the absence of this expansion of educational attainment Canada would have experienced an increase in income inequality between the more- and less-educated similar to that observed in the United States. 


\section{References}

Aghion, Phillipe and Peter Howitt. "A Model of Growth through Creative Destruction," Econometrica March 1992, , v60, n2, p. 323-51.

Autor, David H., Lawrence F. Katz and Alan B. Krueger. "Computing Inequality: Have Computers Changed the Labor Market?" National Bureau of Economic Research Working Paper No. 5956, March 1997.

Bresnahan, Timothy F. and Manuel Trajtenberg. "General Purpose Technologies: 'Engines of Growth'?’ Journal of Econometrics, January 1995, 65, pp. 83-108.

Card, David and Richard B. Freeman, eds. Small Differences That Matter: Labor Markets and Income Maintenance in Canada and the United States. Chicago: University of Chicago Press and NBER, 1993.

David, Paul A. et al. "Computer and Dynamo: The Modern Productivity Paradox in a Not-Too-Distant Mirror," Technology and Productivity: The Challenge for Economic Policy, OECD, 1991.

Freeman, Christopher and Carlota Perez, "Structural Crises of Adjustment, Business Cycles and Investment Behaviour," in Giovanni Dosi, Christopher Freeman, Richard Nelson, Gerald Silverberg, and Luc Soete, eds., Technical change and economic theory, 1988, pp. 38-66.

Freeman, Richard B. and Karen Needels. "Skill Differentials in Canada in an Era of Rising Labor Market Inequality" in David Card and Richard B. Freeman, eds., Small Differences That Matter: Labor Markets and Income Maintenance in Canada and the United States. Chicago: University of Chicago Press and NBER, 1993.

Fortin, Nicole M. and Thomas Lemieux. "Institutional Change and Rising Wage Inequality: Is There a Linkage?" Journal of Economic Perspectives, Spring 1997, 11 (2), pp. 75-96.

Goldin, Claudia. "How America Graduated from High School: 1910 to 1960," National Bureau of Economic Research Working Paper No. 4762, June 1994.

Goldin, Claudia and Lawrence F Katz. "The Decline of Non-Competing Groups: Changes in the Premium to Education, 1890 to 1940," National Bureau of Economic Research Working Paper No. 5202, August 1995.

"Technology, Skill, and the Wage Structure: Insights from the Past," American Economic Review, May 1996, 86 (2), pp. 252-257.

Gottschalk, Peter. "Inequality, Income Growth, and Mobility: The Basic Facts," Journal of Economic Perspectives, Spring 1997, 11 (2), pp. 21-40. 
Greenwood, Jeremy and Mehmet Yorukoglu. "1974," Carnegie-Rochester Conference Series on Public Policy, 1997 (forthcoming).

Griliches, Zvi. "Capital-Skill Complementarity," Review of Economics and Statistics, November 1969, 51, pp. 465-68.

Review, 84, 1, March 1994.

"Productivity, R\&D and the Data Constraint," American Economic

Grossman, Gene and Elhanan Helpman. Innovation and Growth in the World Economy. Cambridge: MIT Press, 1991.

Hammermesh, Daniel S. Labor demand. Princeton, New Jersey: Princeton University Press, 1993.

Helpman, Elhanan and Manuel Trajtenberg. "A Time to Sow and a Time to Reap: Growth Based on General Purpose Technologies," Centre for Economic Policy Research, Discussion Paper: 1080, December 1994.

Johnson, George E. "Changes in Earnings Inequality: The Role of Demand Shifts," Journal of Economic Perspectives, Spring 1997, 11 (2), pp. 41-54.

Katz, Lawrence F. and Kevin M. Murphy. "Changes in Relative Wages, 1963-1987: Supply and Demand Factors," Quarterly Journal of Economics, February 1992, 107(1), pp. 35-78.

Krueger, Alan B. "How Computers Have Changed the Wage Structure: Evidence from Microdata, 1984-1989," Quarterly Journal of Economics, 1993, 108, pp. 33-60.

Lawrence, Robert Z. and Matthew J. Slaughter, "International Trade and American Wages in the 1980s: Giant Sucking Sound or Small Hiccup?" Brookings Papers on Economic Activity, Microeconomics, 1993, 2, pp. 161-210.

Leamer, Edward E. "Wage Inequality from International Competition and Technological Change: Theory and Country Experience," American Economic Review, May 1996, 86 (2), pp.309-314.

Levy, Frank and Richard J. Murnane, "What Skills are Computers Complements With?" American Economic Review, May 1996, 86 (2), pp. 258-262.

Lucas, Robert E., Jr., “On the Mechanics of Economic Development," Journal of Monetary Economics, July 1988, 22, pp. 3-42.

Mankiw, N. Gregory; David Romer, David N. Weil. "A Contribution to the Empirics of Economic Growth,” Quarterly Journal of Economics, May 1992, 107 (2), pp. 407-37. 
Razin, Assaf. "Optimum Investment in Human Capital," The Review of Economic Studies, October 1972, 23 (4), pp. 455-60.

Ricardo, David. The Principles of Political Economy and Taxation, Chapter 31, Richard D. Homewood IL: D. Irwin Inc, 1963.

Romer, Paul M. "Endogenous Technological Change," Journal of Political Economy, 1990, 98, pp. S71-S102.

Rosen, Sherwin. "Short-Run Employment Variation on Class-I Railroads in the U.S., 1947-63," Econometrica, 1968, 36, pp. 511-29.

Rosenberg, Nathan. "Technological Change in the Machine Tool Industry, 1840-1910," Journal of Economic History, December 1963, 23, pp 414-43. Reprinted in Nathan Rosenberg, Perspectives on Technology, Armonk, NY: M. E. Sharpe, 1976.

Sachs, Jeffrey and Howard J. Shatz. "Trade and Jobs in U.S. Manufacturing." Brookings Papers on Economic Activity, Macroeconomics, 1994, 1, pp. 1-84.

Samuelson, Paul A. Economics: An introductory analysis. New York: McGraw-Hill Book Company, 1964.

. " Mathematical Vindication of Ricardo on Machinery," The Journal of

Political Economy, April 1988, 96 (2) pp. 274-282.

Tinbergen, Jan. Income Differences: Recent Research. Amsterdam: North Holland, 1975.

Topel, Robert H. "Factor Proportions and Relative Wages: The Supply-Side

Determinants of Wage Inequality," Journal of Economic Perspectives, Spring 1997, 11 (2), pp. 55-74.

Wood, Adrian. North-South Trade, Employment and Inequality. Oxford: Clarendon Press, 1994. 


\section{Relative wages in US and Canada}

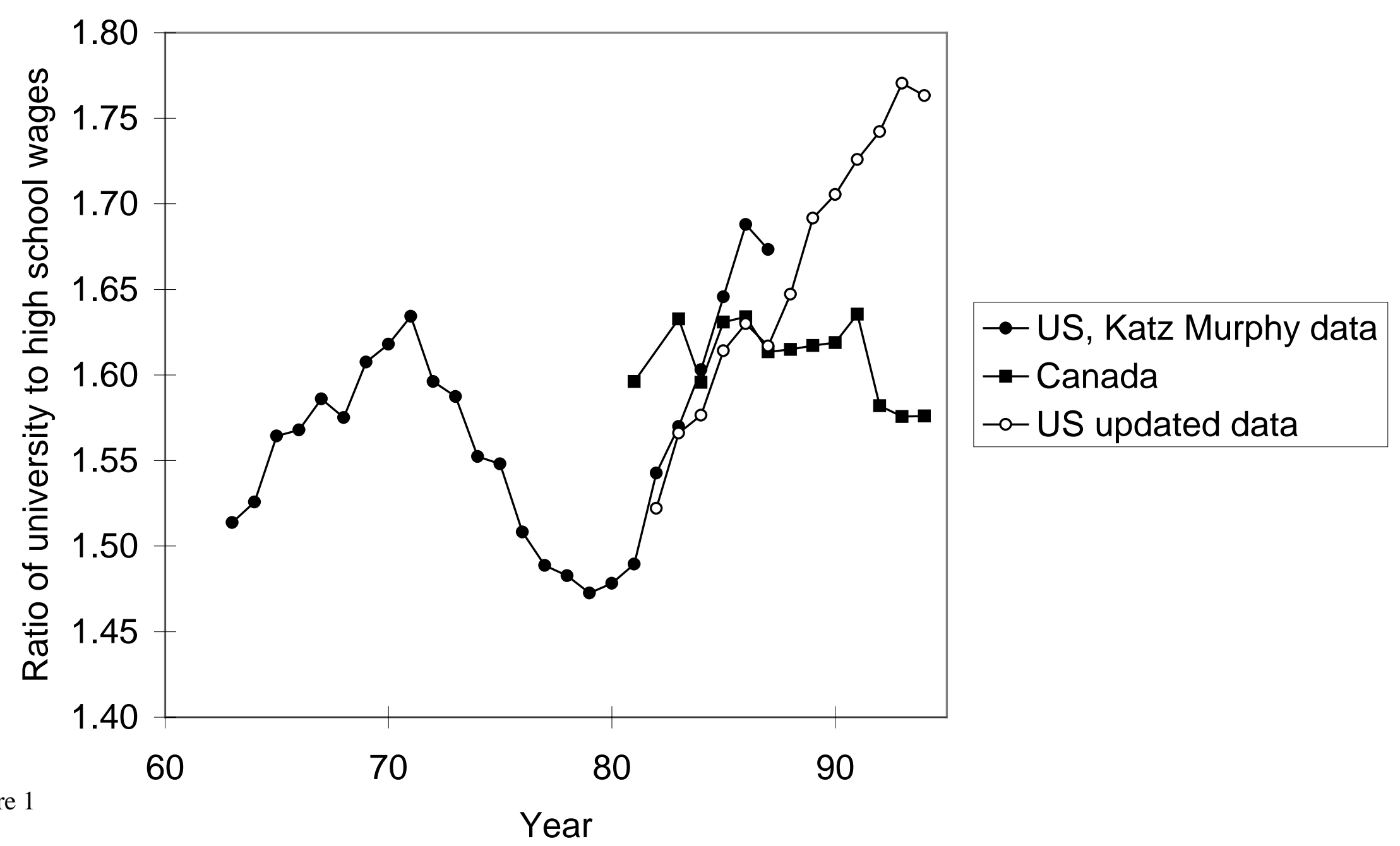




\section{Alternative weights for quantity series used with Katz-Murphy data}

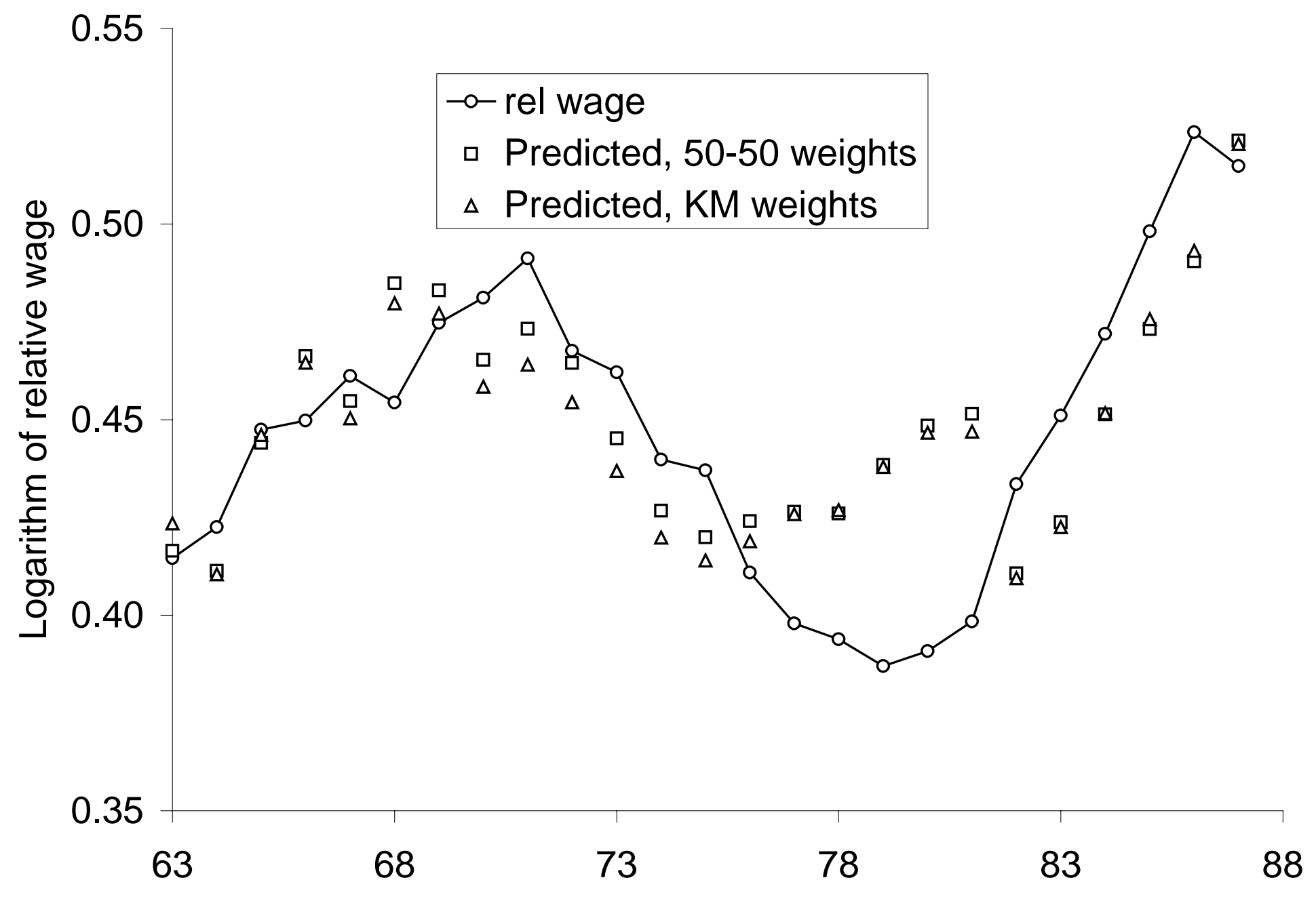

Figure 2 


\section{Implied values of $g(t)$ and trendline for various values of the elasticity of substitution}

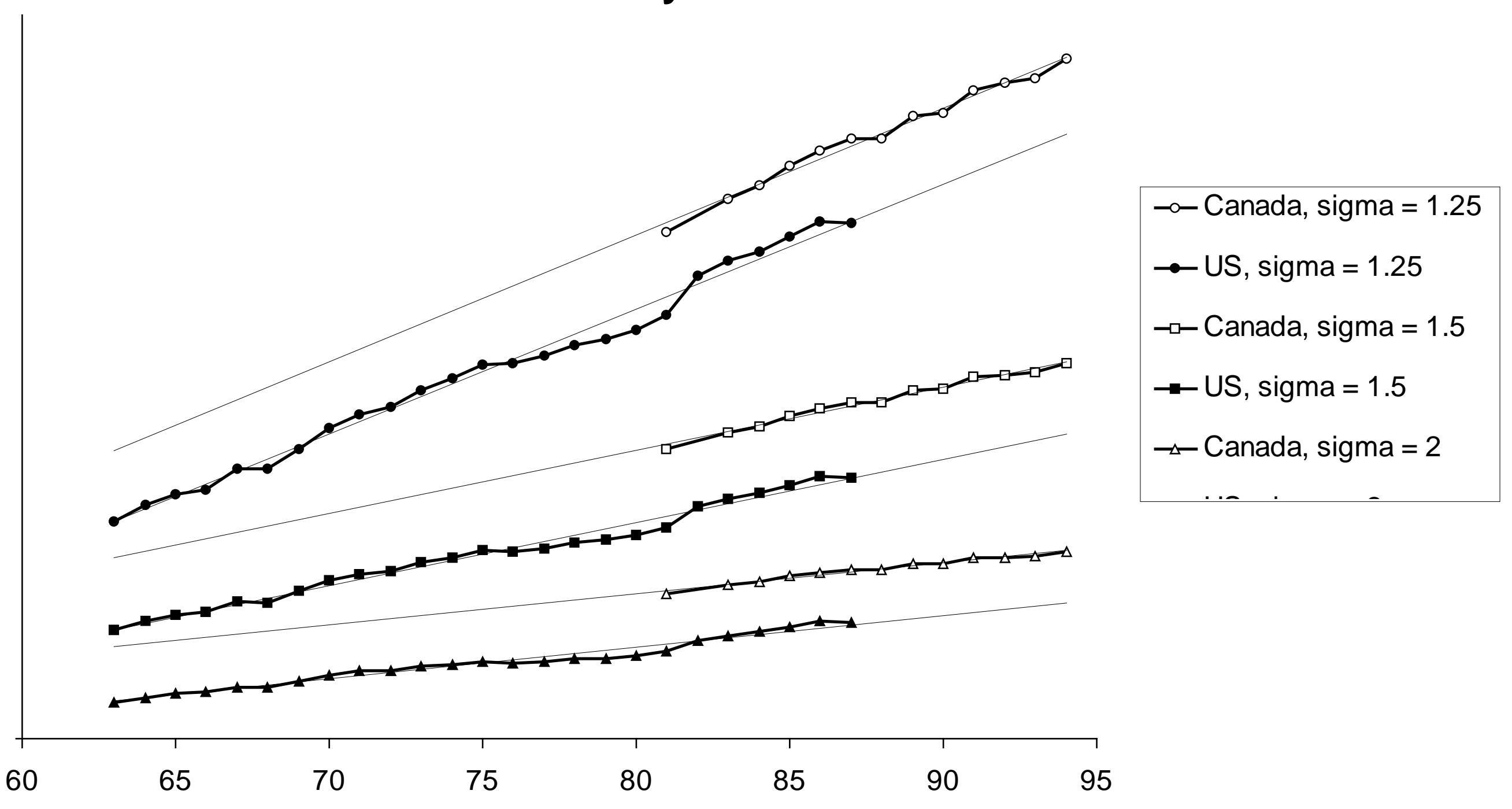

Figure 3 


\section{Predicted and actual log wages in the US and Canada}

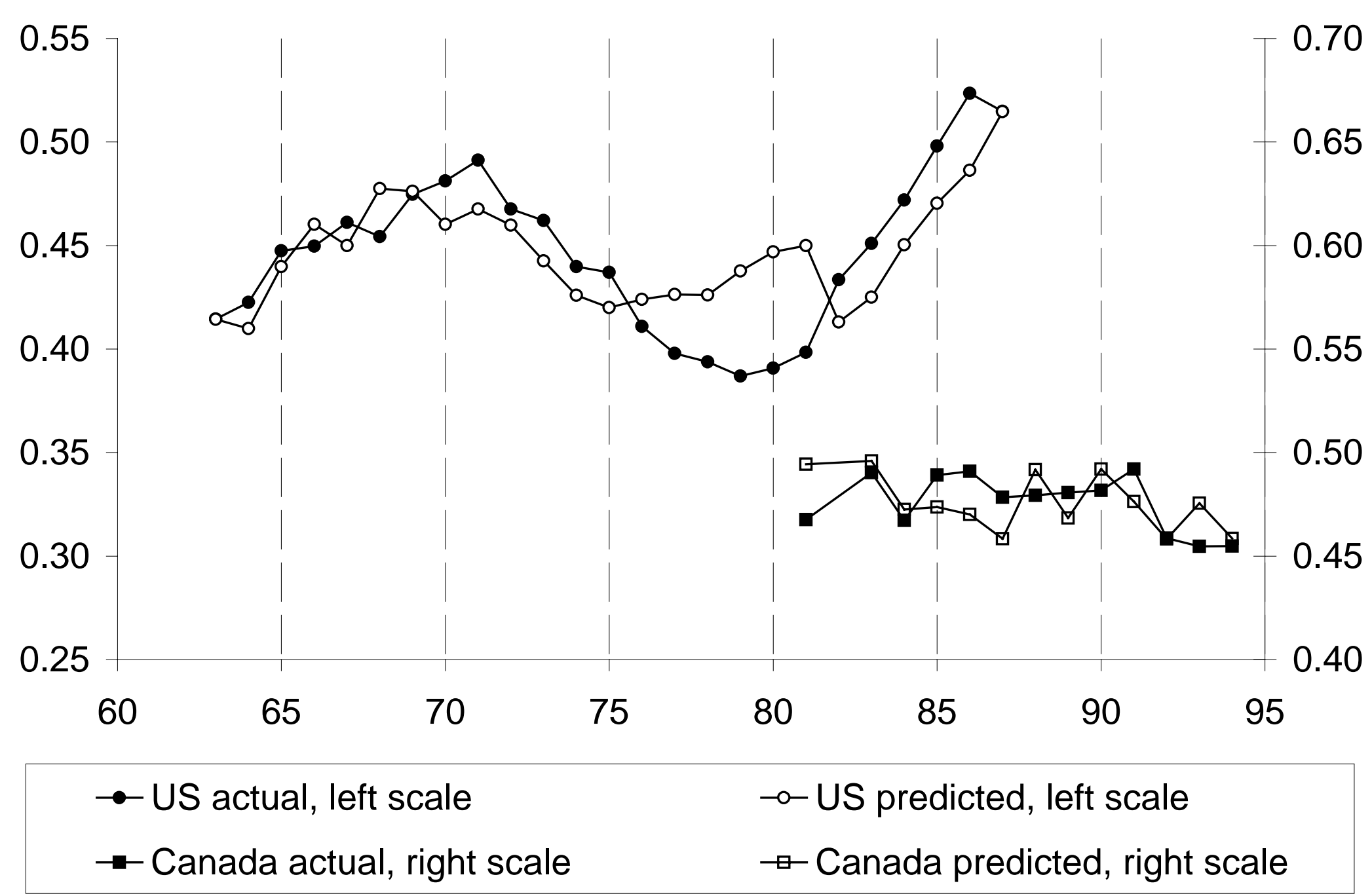




\section{Average annual changes in relative quantities and}

relative wages

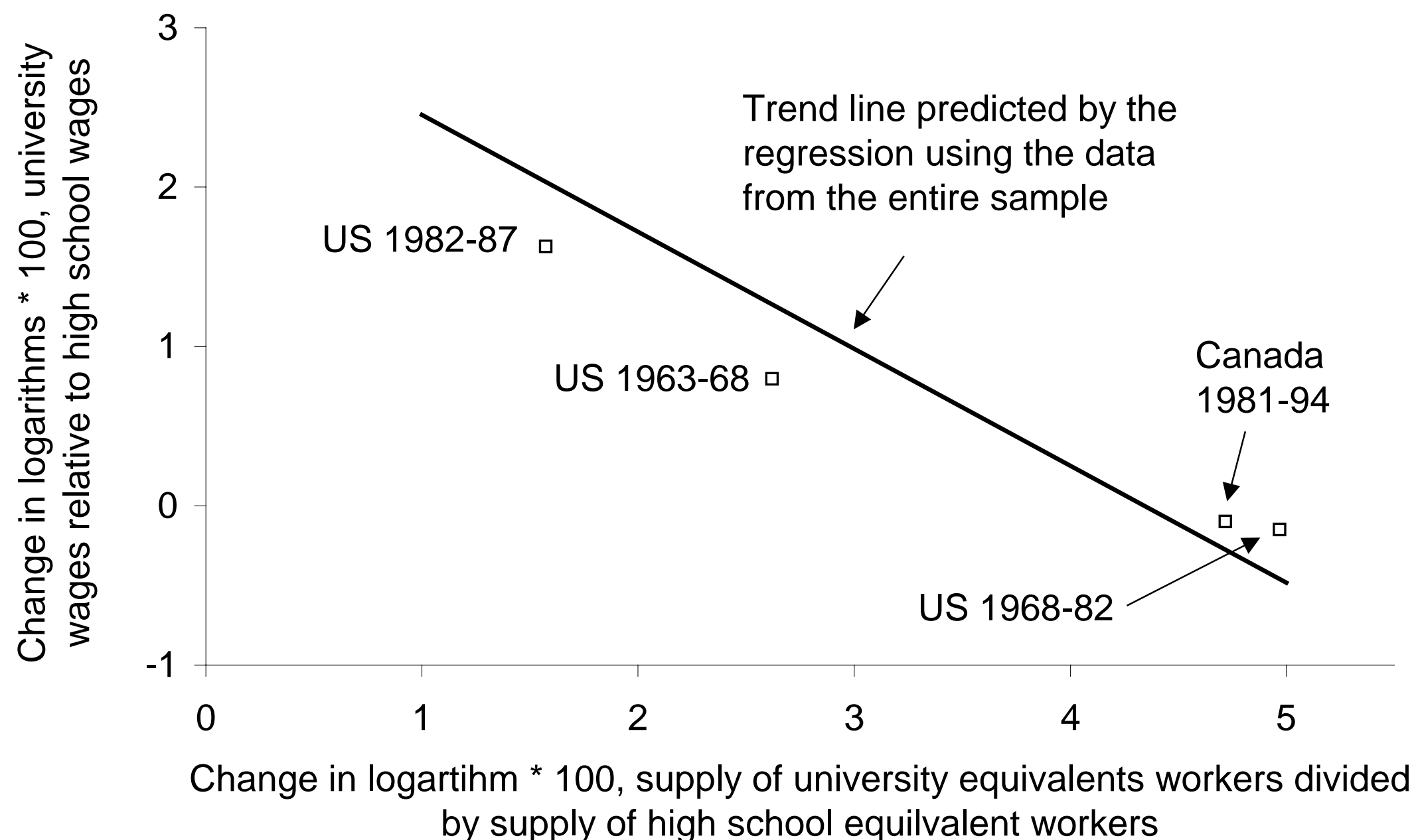




\section{Tests for trend break}

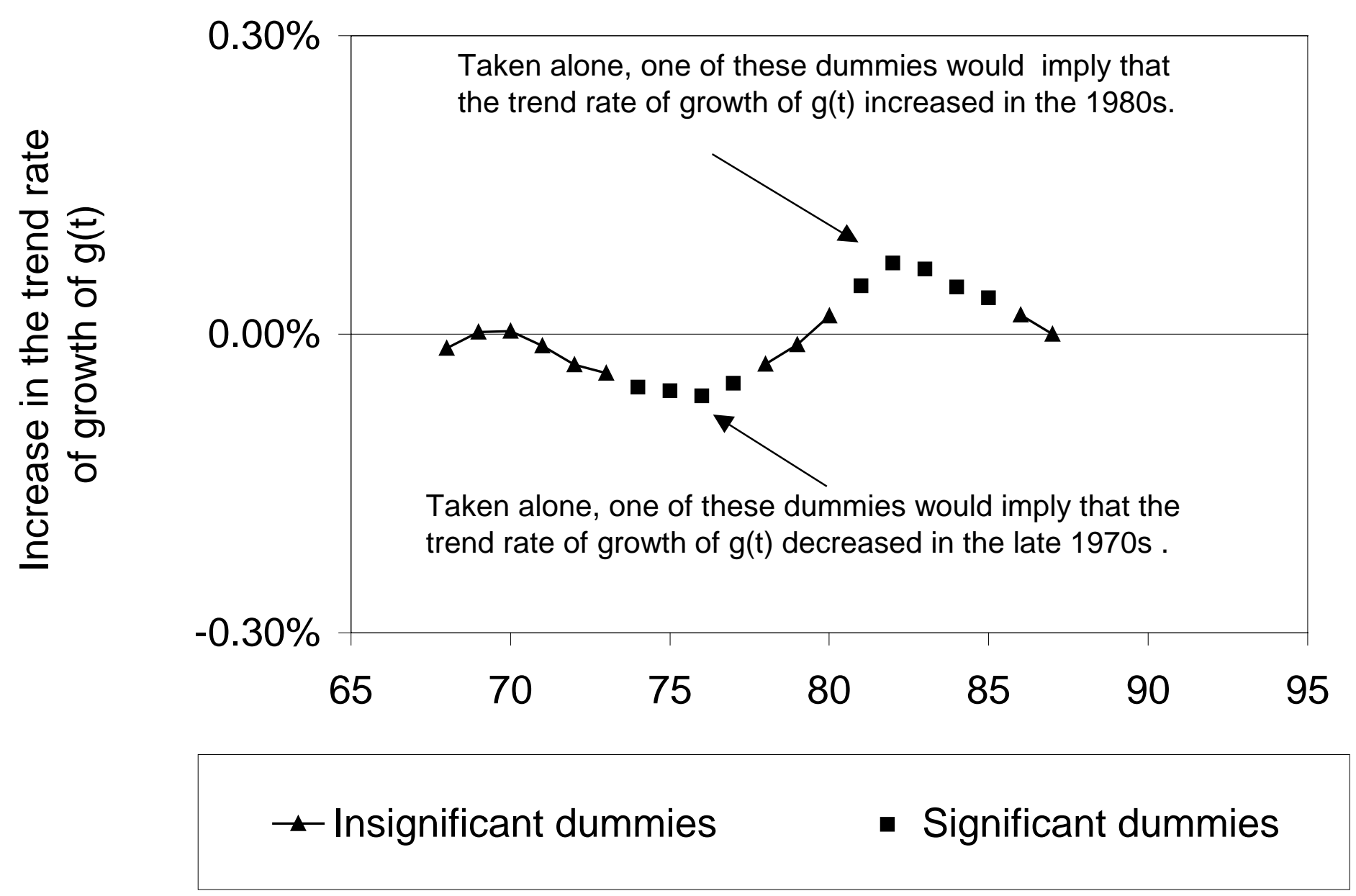

Figure 6 